\title{
Changes in Fatty Acid Composition and Saturation in Leaves and Roots of Creeping Bentgrass Exposed to High Soil Temperature
}

\author{
Xiaozhong Liu' ${ }^{1}$ and Bingru Huang ${ }^{2}$ \\ Department of Plant Biology and Pathology, Rutgers University, New Brunswick, NJ 08901
}

\begin{abstract}
ADDITIONAL INDEX WORDS. Agrostis palustris, heat stress, lipid
Abstract. Previous studies found that high soil temperature is more detrimental than high air temperature for the growth of creeping bentgrass (Agrostis palustris L.). The objective of the study was to investigate changes in fatty acid composition and saturation levels in leaves and roots for creeping bentgrass exposed to high soil temperature. Shoots and roots of 'Penncross' plants were subjected to a differential air/soil temperature of $20 / 35^{\circ} \mathrm{C}$ in a growth chamber. Soil temperature was controlled at $35^{\circ} \mathrm{C}$ using an immersion circulating heater in water bath. Shoot injury induced by high soil temperature was evaluated by measuring level of lipid peroxidation expressed as malonyldialdehyde (MDA) content, chlorophyll content, and photochemical efficiency (Fv/Fm) of leaves. MDA content increased while chlorophyll content and $\mathrm{Fv} / \mathrm{Fm}$ decreased at high soil temperature. The content of total fatty acids and different species of fatty acids were analyzed in both leaves and roots. Total fatty acid content in leaves increased initially at 5 days of high soil temperature and then decreased at 15 days, while total fatty acid content in roots decreased, beginning at 5 days. Linolenic acid was the major fatty acid in leaves and linoleic acid and palmitic acid were the major fatty acids in roots of creeping bentgrass. Leaf content of all fatty acid components except oleic acid increased initially and then decreased at high soil temperature. Root content of all fatty acid components except palmitoleic acid and oleic acid decreased, beginning at $5 \mathrm{~d}$ of high soil temperature. Oleic acid in leaves and palmitoleic and oleic acid in roots did not change during the entire experimental period. Leaf content of saturated fatty acids and unsaturated fatty acids increased during the first 5 to 10 days of high soil temperature and decreased at 15 and 25 days, respectively. Root content of saturated fatty acids and unsaturated fatty acids decreased beginning at 5 days of high soil temperature. Double bond index decreased in both leaves and roots. High soil temperature induced changes in fatty acid composition and saturation levels in leaves and roots, and this could be associated with physiological damages in leaves even though only roots were exposed to high temperature.
\end{abstract}

High temperature is a critical factor limiting growth and physiological function for cool-season species in the summer in warm climatic regions. High soil temperature is more detrimental than high air temperature for many plant species, and inhibits various growth and physiological activities of shoots and accelerates leaf senescence (Kuroyanagi and Paulsen, 1988; Ruter and Ingram, 1992; Udomprasert et al., 1995; Xu and Huang, 2000a, 2000b; Ziska, 1998). Understanding of mechanisms of plant tolerance to high soil temperature is of significance to develop or select for heat tolerant plant materials.

Physiological injuries and leaf senescence caused by heat stress are associated with cellular membrane damage, leading to solute leakage from cells and disruption of cell function (Blum and Ebercon, 1981; Marcum, 1998; Paulsen, 1994). Membrane disruption is associated with increased membrane lipid peroxidation, a process in which free radicals cause chemical bonds to form between fatty acid molecules that properly should be independent (Foyer et al., 1994; Smirnoff, 1993). The double bonds in the unsaturated fatty acid are easily attacked by hydroxyl free radical (.OH) under environmental stresses (Elstner, 1982; Foyer et al., 1994; Halliwell, 1984; Smirnoff, 1993). Fatty acid composition and saturation level affect membrane integrity and thus, plant tolerance to heat stress (Murakami et al., 2000). Increases in the degree of saturation enhance heat stability of lipids, contributing

Received for publication 17 May 2004. Accepted for publication 11 Aug. 2004.

'Postdoctoral Research Associate. Current address: ValentBioSciences Corporation, Long Grove, IL 60047

${ }^{2}$ Associate Professor. Corresponding author. E-mail address: huang@aesop. rutgers.edu to plant tolerance to high temperature in various species (Grove et al., 2000; Pearcy, 1978; Raison et al., 1982). Thomas et al. (1986) reported that thermal stability of pea (Pisum sativum L.) plants increased following catalytic hydrogenation of membrane lipids. Mutants deficient in lipid unsaturation in Arabidopsis thaliana (L.) Heynh. and Glycine max (L.) Merr. had enhanced thermal tolerance (Alfonso et al., 2000; Hugly et al., 1989; Kunst et al., 1989). However, some studies showed that the severity of heat stress injury is not associated with the alteration in the level of saturation of membrane lipids (Gombos et al., 1994; Peters and Chin, 2003; Vigh et al., 1993).

Creeping bentgrass is a heat-sensitive cool-season grass species, and its growth and quality often decline under heat stress (Fry and Huang, 2004). Larkindale and Huang (2004) reported that when both shoots and roots were exposed to high temperature (35 ${ }^{\circ} \mathrm{C}$ ), leaf fatty acids showed increases in the saturation level, but root fatty acid saturation level did not change in three cultivars of creeping bentgrass. High soil temperature alone induces leaf senescence and other shoot physiological activities in creeping bentgrass (Huang et al., 2001; Liu and Huang, 2002, Wang et al., 2004). Changes in fatty acid composition and saturation level in both shoots and roots under high soil temperature conditions have not been investigated extensively. Furthermore, it is not clear whether leaf injury induced by high soil temperature is associated with changes in fatty acid composition and/or saturation level in creeping bentgrass. Understanding effects of high soil temperature on fatty acids would provide insights into how plant survive in hot environments.

The objectives of this study were to (a) examine changes in fatty acid composition and saturation level in leaves and roots 
of creeping bentgrass exposed to high soil temperature; (b) determine whether leaf injury induced by high soil temperatures was related to changes in the composition and/or saturation level of lipids. Physiological injury in leaves was evaluated by measuring the level of lipid peroxidation, chlorophyll content, and photochemical efficiency.

\section{Materials and Methods}

Plant materials. Ninety-six sod pieces $(5 \mathrm{~cm}$ diameter, $1.5 \mathrm{~cm}$ thick) of 'Penncross' creeping bentgrass were transferred into bags made from clear polyethylene tubing ( $5 \mathrm{~cm}$ diameter, $40 \mathrm{~cm}$ long) filled with washed white sand (0.2-0.5 mm particle size). Holes were made at the bottom of the bags for drainage. Each bag was placed in an opaque polyvinylchloride (PVC) tube which bottom was covered with nylon screen $(5 \mathrm{~cm}$ i.d., $40 \mathrm{~cm}$ long). Ninetysix PVC tubes were installed vertically in each water bath $(60$ $\mathrm{cm}$ long $\times 50 \mathrm{~cm}$ wide $\times 50 \mathrm{~cm}$ deep) with the lower open end of each tube exposed from the bottom of the water bath for drainage. The tubes were designed to enable plant growth to occur in welldrained sand in polyethylene tubes, while root-zone temperature was controlled at constant levels. The detailed description of the water bath was presented in Wang et al. (2004).

Plants were maintained in the water baths in a walk-in growth chamber (Environmental Growth Chambers, Inc., Chagrin Falls, Ohio) for $60 \mathrm{~d}$ before treatments were imposed. The temperature in the growth chamber was $20^{\circ} \mathrm{C}$ day/ $16{ }^{\circ} \mathrm{C}$ night, relative humidity was $65 \%$, photosynthetic photon flux density was 500 $\mu \mathrm{mol} \cdot \mathrm{m}^{-2} \cdot \mathrm{s}^{-1}$, and photoperiod was $12 \mathrm{~h}$. Turf was mowed daily at 3-4 $\mathrm{mm}$ with a scissors, irrigated once daily until there was drainage from the bottom of PVC tubes, and fertilized weekly with $40 \mathrm{~mL}$ full-strength Hoagland's nutrient solution (Hoagland and Arnon, 1950). When treatments were imposed, plants were not mowed to allow growth in order to obtain sufficient tissues for the measurement of lipid peroxidation and fatty acid content.

Treatments AND EXPERIMENTAL DESIGN. Forty-eight tubes of plants were maintained at a constant air/soil temperature of 20 ${ }^{\circ} \mathrm{C}$ as the control treatment, which were exposed to ambient air in the growth chamber. For the high soil temperature treatment, shoots of plants (48 tubes) were maintained at the optimum air temperature (day/night at $20{ }^{\circ} \mathrm{C}$ ) while roots were exposed to a constant day/night temperature of $35^{\circ} \mathrm{C}$ in the water bath as described above. The entire root-zone (40-cm-long sand column in a polyethylene bag) was kept in the water bath while the turf canopy was kept approximately $1.0 \mathrm{~cm}$ above the water level in the water bath with the water level maintained at the top edge of the water bath. Water bath temperature was controlled with an immersion circulating heater. Root-zone temperature was monitored daily using thermocouples placed into the root-zone at a depth of $10 \mathrm{~cm}$ (one thermocouple in each of eight tubes). The root-zone temperature at $10-\mathrm{cm}$ depth during the study was maintained constantly at $35^{\circ} \mathrm{C}$ for the high soil temperature treatment and at $20^{\circ} \mathrm{C}$ for the control treatment. Canopy temperature was measured daily with an infrared thermometer (Raytek; Spectrum Technologies, Santa Cruz, Calif.) by positioning it at a $45^{\circ}$ angle and $10-\mathrm{cm}$ from the canopy surface. Canopy temperature averaged $23 \pm 0.6^{\circ} \mathrm{C}$ for the high soil temperature treatment and 20 ${ }^{\circ} \mathrm{C}$ for the control during the treatment period. The experiment was terminated at $40 \mathrm{~d}$ of treatment.

The experiment was a completely randomized design with repeated measures. The high soil temperature treatment was repeated in four water baths placed in four growth chambers.
Measurements were made at $0,5,10,15,20,30$, and $40 \mathrm{~d}$ of treatment. Each parameter was measured on four sub-samples for each of four replicates. Effects of time of treatment, temperature, and their interactions were determined by analysis of variance according to the general linear model procedure of SAS (SAS Inst., Cary, N.C.). Significant interaction between treatment and time of treatment was detected. Differences between treatment means were separated by the least significance difference (LSD) test at 0.05 probability level at a given day of treatment.

Measurements. Relative chlorophyll content was estimated with a chlorophyll meter expressed as an index (range 0 to 999) (model CM 1000; Spectrum Technologies, Plainfield, Ill.). Leaf photochemical efficiency was estimated by measuring chlorophyll fluorescence [a ratio of variable to maximum photo yield (Fv/ Fm)] of individual leaves with a Fluorescence Induction Monitor (BioScientific Ltd., Herts, U.K.). The lipid peroxidation level was determined in terms of malonyldialdehyde (MDA) content by the method of Heath and Packer (1968). Fresh leaves (0.5 g) were extracted in $10 \mathrm{~mL}$ of $5 \%(\mathrm{w} / \mathrm{v})$ trichloroacetic acid. Homogenates were centrifuged at $4000 g_{\mathrm{n}}$ for $10 \mathrm{~min}$. The supernatant $(2 \mathrm{~mL})$ was mixed with $2 \mathrm{~mL}$ of $0.67 \%(\mathrm{v} / \mathrm{w})$ thiobarbituric acid and then boiled for $20 \mathrm{~min}$ and centrifuged after cooling. Absorbance of the solution was read at 532 and $600 \mathrm{~nm}$. The absorbance for non-specific absorption at $600 \mathrm{~nm}$ was subtracted from the value at $532 \mathrm{~nm}$. The amount of MDA (red pigment) was calculated using the adjusted absorbance and the extinction coefficient 155 $\mathrm{mm} \cdot \mathrm{cm}^{-1}$ (Heath and Packer, 1968).

Fatty acids were extracted from fresh tissues and analyzed using gas chromatography (GC) according to the method described in Cyril et al. (2002). A 2-mL sample of $1 \mathrm{M} \mathrm{H}_{2} \mathrm{SO}_{4}$ in methanol and $200 \mu \mathrm{g}$ heptadecanoic acid (17:0, internal standard) were added in each screw-capped tube containing $200 \mathrm{mg}$ of leaves or roots. $\mathrm{N}_{2}$ gas was blown over to drive out air, and tubes were then sealed immediately. Samples were methylated at $80^{\circ} \mathrm{C}$ for $90 \mathrm{~min}$. After the tubes were cooled, a $3.0 \mathrm{~mL} 0.9 \% \mathrm{NaCl}(\mathrm{w} / \mathrm{v})$ and $200 \mu \mathrm{L}$ of hexane were added, mixed, and spun at $2000 g_{n}$ for $2 \mathrm{~min}$. The hexane phase (upper phase) was used for GC analysis. Different components of fatty acids were measured using a gas chromatograph (model 5973; Hewlett Packard, Wilmington, Del.) with mass selective detector (model 6890; Hewlett Packard). A 2- $\mu \mathrm{L}$ sample was injected into a $\mathrm{C} 18$ column. The running conditions were as follows: $1 \mathrm{~mL} \cdot \mathrm{min}^{-1}$ column flow, $2 \mathrm{kPa}$ pressure, 170 ${ }^{\circ} \mathrm{C}$ initial temperature, $230^{\circ} \mathrm{C}$ ramp temperature, $280^{\circ} \mathrm{C}$ detector temperature, and $\mathrm{He}$ as carrier gas. Individual fatty acid content was quantified based on the ratio of its peak area over that of the internal standard. The fatty acids examined in this study include palmitic acid (16:0), palmitoleic acid (16:1), stearic acid (18:0), oleic acid (18:1), linoleic acid (18:2), and linolenic acid (18:3).

Fatty acid unsaturation was expressed as double bond index (DBI) (Vassilev et al., 2003). It was calculated using the following formula: $\mathrm{DBI}=\{[\mathrm{C} 16: 1]+[\mathrm{C} 18: 1]+2 \times[\mathrm{C} 18: 2]+3 \times[\mathrm{C} 18: 3]\}$, where square brackets represented the percentage of the total lipid content which was made up by each lipid species.

\section{Results}

Physiological responses. The level of lipid peroxidation, expressed as malonyldialdehyde (MDA) content, increased above the control level at $10 \mathrm{~d}$ of high soil temperature treatment (Fig. 1A). The increase in MDA content was more pronounced with increasing treatment duration. By $40 \mathrm{~d}$, MDA content at high soil temperature was 11 times the control level (Fig. 1A). 


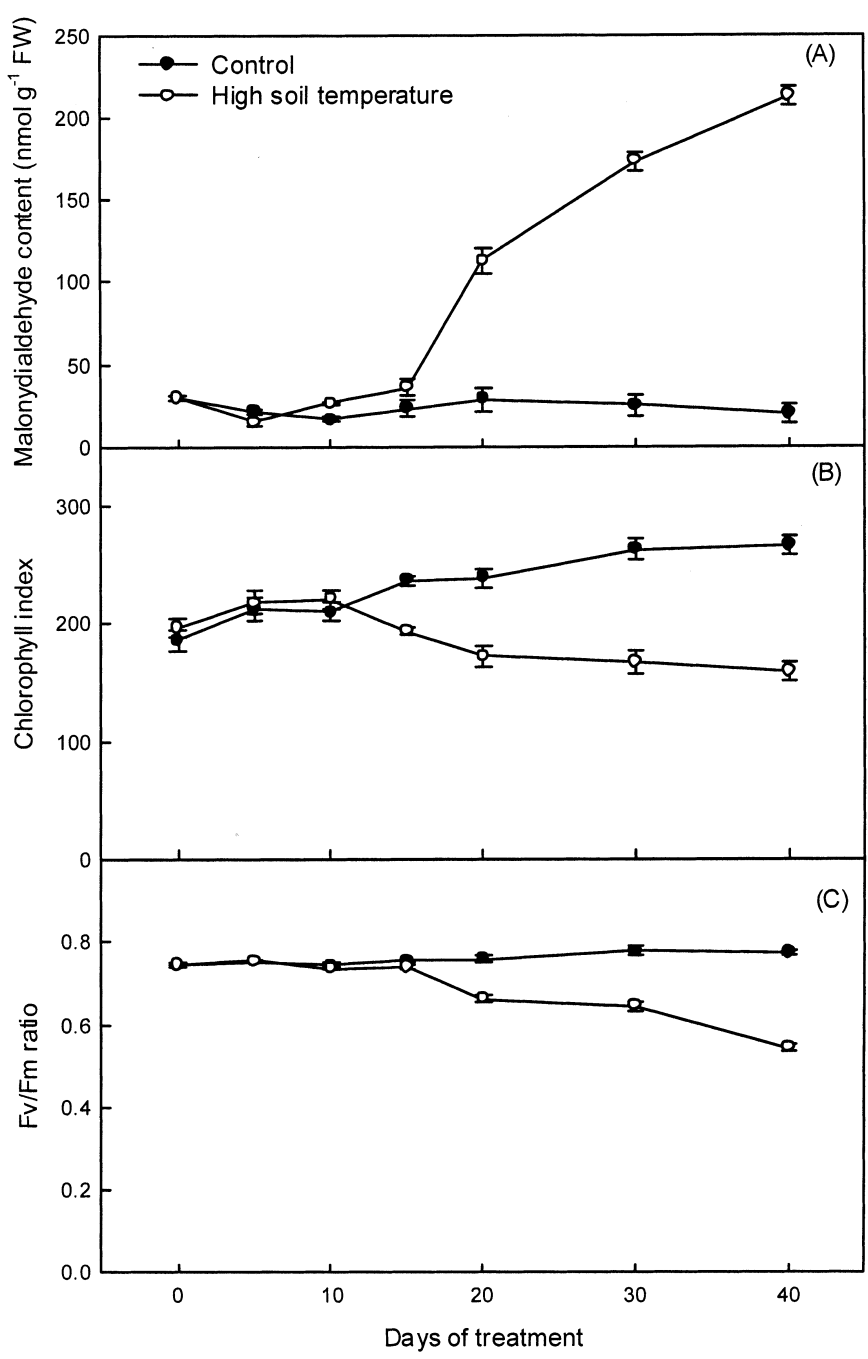

Fig. 1. Effects of high soil temperature on leaf malonylaldehyde (MDA) content (A), chlorophyll index (B), and photochemical efficiency $(\mathrm{Fv} / \mathrm{Fm})(\mathbf{C})$ for creeping bentgrass. Malonylaldehyde content was expressed as nmol malonylaldehyde per gram fresh weight (FW) of tissues. Control = air/soil temperature of 20/20 ${ }^{\circ} \mathrm{C}$. High soil temperature $=$ air/soil temperature of $20 / 35^{\circ} \mathrm{C}$. Vertical bars on the lines represent the values for the least significance difference at $P=0.05$ $(n=4)$ for treatment comparison at a given day of treatment.

Chlorophyll index decreased below the control level, beginning at $15 \mathrm{~d}$ of treatment (Fig. 1B). By $40 \mathrm{~d}$, chlorophyll index at high soil temperature was $40 \%$ lower than the control level.

Leaf photochemical efficiency (Fv/Fm ratio) decreased below the control level, beginning at $20 \mathrm{~d}$ of treatment (Fig. 1C). By $40 \mathrm{~d}, \mathrm{Fv} / \mathrm{Fm}$ at high soil temperature was $30 \%$ lower than the control level (Fig. 1C)

TOTALFATTYACIDCONTENT. Total fatty acid content in the leaves increased at $5 \mathrm{~d}$ of high soil temperature and then decreased below the control level at $15 \mathrm{~d}$ of treatment (Fig. 2A). By $40 \mathrm{~d}$, total fatty acid content in leaves at high soil temperature was $63 \%$ lower than the control level. Total fatty acid in roots decreased below the control level at $5 \mathrm{~d}$ of treatment (Fig. 2B). By $40 \mathrm{~d}$, total fatty acid content at high temperature was $53 \%$ lower than the control level. Total fatty acid content of roots was approximately four times less than that of leaves.

FAtTYACID COMPosition. Six fatty acids were detected in leaves and roots of control and stressed plants, including palmitic acid (16:0), palmitoleic acid (16:1), stearic acid (18:0), oleic acid (18:1), linoleic acid (18:2), and linolenic acid (18:3). Linolenic acid accounted for $65 \%$ of total fatty acids, followed by palmitic acid and linoleic acid, accounting for $14 \%$ and $13 \%$ of total fatty acids, respectively. Palmitoleic acid, stearic acid, and oleic acid were the minor fatty acids in leaves, accounting for $4 \%, 3 \%$, and $1 \%$ of the total fatty acids, respectively (Fig. 3A). Unsaturated fatty acids were the predominant fatty acids in leaves, accounting for $83 \%$ of the total fatty acids while saturated fatty acids only accounted for $17 \%$. Fatty acids with $18-\mathrm{C}$ and $16-\mathrm{C}$ in leaves accounted for $82 \%$ and $18 \%$ of the total fatty acids, respectively (Fig. 3A).

In roots, linoleic acid, palmitic acid, linolenic acid, and oleic acid in roots accounted for $39 \%, 26 \%, 16 \%$, and $10 \%$ of the total fatty acids, respectively. Stearic acid and palmitoleic acid were the minor fatty acids in roots, which accounted for $6 \%$ and $3 \%$ of the total fatty acids, respectively (Fig. 3B). Unsaturated fatty acids were also predominant in roots, which accounted for $68 \%$ of total fatty acid while saturated fatty acids accounted for $32 \%$. Fatty acids with $18-\mathrm{C}$ and $16-\mathrm{C}$ in roots accounted for $71 \%$ and $29 \%$ of total fatty acids, respectively (Fig. 3B).

Changes in 16-C fatTy ACID. In leaves, palmitic (Fig. 4A) and palmitoleic (Fig. 4B) acid content increased at the beginning (5 d) of high soil temperature treatment, and then declined rapidly with increasing treatment duration. By $40 \mathrm{~d}$, palmitic acid content and palmitoleic acid content in leaves were $51 \%$ and $64 \%$ lower than the control level, respectively (Fig. 4A, B).

Root palmitic acid content decreased below the control level at $5 \mathrm{~d}$ of the high soil temperature. By $40 \mathrm{~d}$, root palmitic acid content was 55\% lower than the control level (Fig. 4C). Root palmitoleic acid content was not affected by high soil temperature (Fig. 4D).

Changes in 18-C fatty ACID. The content of all 18-C fatty acids in leaves increased initially at $5 \mathrm{~d}$ of high soil temperature treatment, and then decreased with treatment duration (Fig. 5 A, B, C, D). The content of stearic (Fig. 5A), linoleic (Fig. 5C), and linolenic acids (Fig. 5D) decreased by 50\%, 57\%, and $78 \%$ compared to the control level by $40 \mathrm{~d}$ of treatment, while no difference in oleic acid (Fig. 5B) was detected between the control and high soil temperature treatment after $10 \mathrm{~d}$.

Stearic acid content in roots decreased to below the control level, beginning at $10 \mathrm{~d}$ of the high soil temperature and was $48 \%$ lower than the control level by $40 \mathrm{~d}$ (Fig. 6A). Oleic acid content was not different between the control and high soil temperature treatment during most of the experimental periods (Fig. 6B). Root linoleic and linolenic acid content decreased to below the control level, beginning at $5 \mathrm{~d}$ of treatment (Fig. $6 \mathrm{C}$ and D).

Changes in Fatty ACID SATURation LeVel. Double bond index (DBI) of lipids in leaves at high soil temperature decreased during the treatment and was $13 \%$ lower than the control by $40 \mathrm{~d}$ (Fig. 7A). Root DBI decreased by $10 \%$ compared to the control level, beginning at $20 \mathrm{~d}$ of treatment (Fig. 7B).

\section{Discussion}

Leaf photochemical efficiency is a measure of the integrity of chloroplast and electron transport efficiency of photosystem II (Schreiber and Bilger, 1987). Malonyldialdehyde content reflects the level of lipid peroxidation, which is positively associated with leaf senescence (Heath and Packer, 1968). Declining chlorophyll content in leaves is an indication of leaf senescence (Thomas et al., 2002). The increase in MDA content (Fig. 1A) and the decrease in chlorophyll (Fig. 1B) and Fv/Fm (Fig. 1C) at high soil temperature indicated that high soil temperature induced membrane 


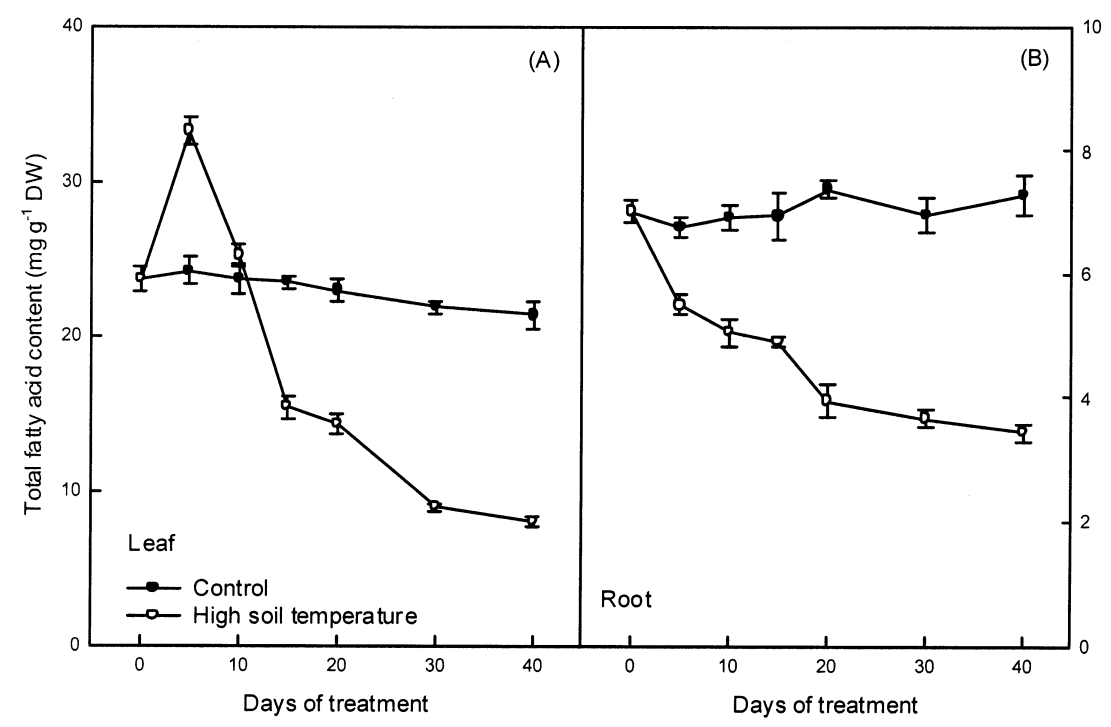

Fig. 2. Effects of high soil temperature on total fatty acid content in leaves (A) and roots (B) for creeping bentass. Fatty acid content was expressed as $\mathrm{mg}$ fatty acid per gram dry weight (DW) of tissues. Control $=$ air/soil temperature of $20 / 20{ }^{\circ} \mathrm{C}$. High soil temperature $=$ air/soil temperature of $20 / 35^{\circ} \mathrm{C}$. Vertical bars represent the values of the least significance difference at $P=0.05(\mathrm{n}=4)$ for treatment comparison at a given day of treatment.

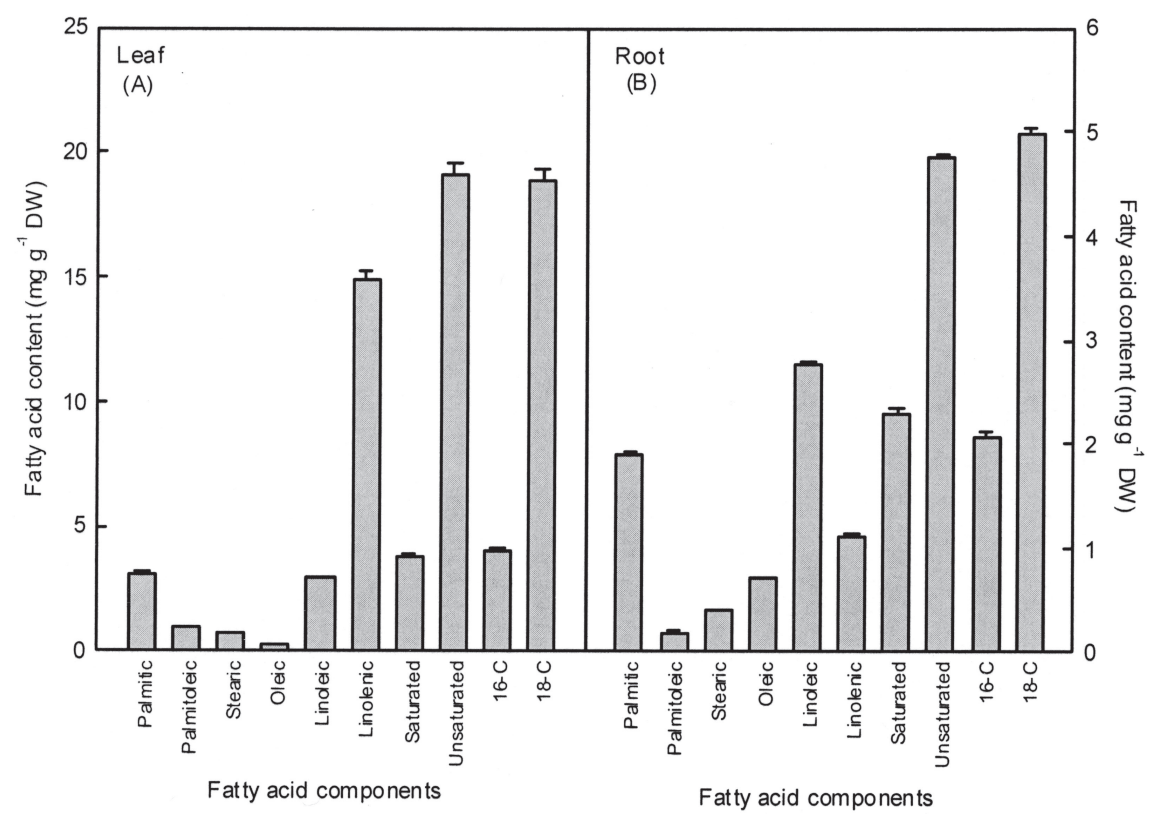

Fig. 3. Fatty acid composition in leaves (A) and roots (B) for creeping bentgrass. The "unsaturated" was the total content of palmitoleic acid (16:1), oleic acid (18:1), linoleic acid (18:2), and linolenic acid (18:3). The "saturated" was the total content of palmitic acid (16:0) and stearic acid (18:0). The "16-C" was the total content of palmitoleic acid (16:1) and palmitic acid (16:0). The "18-C" was the total content of stearic acid (18:0), oleic acid (18:1), linoleic acid (18:2), and linolenic acid (18:3). Fatty acid content was expressed as mg fatty acid per gram dry weight (DW) of tissues.

lipid peroxidation, caused damages to chloroplast membranes, and accelerated leaf senescence. Visual turf quality also declined during the study period, beginning at $15 \mathrm{~d}$ of stress (personal observation). These results are similar to previous reports (Huang et al., 2001; Liu and Huang, 2002) and suggest that physiological injury and leaf senescence induced by high soil temperature could be related to changes in cell membrane properties.

The composition of fatty acids influences fluidity and structure of cell membrane lipid bilayers, which changes with temperature (Cyril et al., 2002; Grove et al., 2000; Vigh et al., 1993). In the present study, total fatty acid content (Fig. 2A) and the content of individual fatty acids (palmitic acid - 16:0, palmitoleic acid - 16:1, stearic acid - 18:0, oleic acid - 18:1, linoleic acid - 18:2, and linolenic acid - 18:3) in leaves (Fig. 4 and 5) transiently increased at $5 \mathrm{~d}$ of high soil temperature. However, this transient increase in fatty acid content was not exhibited in roots (Fig. 6). In this study, leaves were exposed to optimum air temperature while roots were directly exposed to high soil temperature stress. In a previous study, transient increases in total fatty acid content in leaves were also observed within $7 \mathrm{~d}$ when both leaves and roots of creeping bentgrass were exposed to high temperature (Larkindale and Huang, 2004). The significance of transient increases in fatty acid content in leaves is not clear, but it may reflect temporal acclimation to high soil temperature. A signal produced in roots at high soil temperature may trigger the synthesis of new pattern of fatty acid composition in leaves. This pattern of fatty acid could be related, at least temporally, to the acclimation of leaves to high temperature. Heatacclimated plants have increased production of saturated fatty acid in leaves (Larkindale and Huang, 2004). Many of the measured changes in lipid composition during heating have been done exclusively in the thylakoid membranes (Grove et al., 2000; Sharkey, 2000), and previous studies suggest that changes in the composition of thylakoid membranes are more sensitive to heat than the plasma membrane (Horvath et al., 1998). These results could partially explain the transient increase of fatty acid content observed in leaves rather than in roots.

The decline in the content of total fatty acids after $5 \mathrm{~d}$ and $15 \mathrm{~d}$ of high soil temperature in leaves (Fig. 2A) and roots (Fig. 2B), respectively, indicated that high soil temperature either inhibited fatty acid synthesis and/or stimulated fatty acid breakdown. The extent of decrease of unsaturated fatty acid content was more pronounced than the decline of saturated fatty acid in both roots and leaves. In addition, fatty acids with more double bonds in both leaves and roots decreased earlier and to a greater extent than fatty acids with less or no double (Fig. 3). The only exception was oleic acid in leaves and roots and palmitoleic acid in roots, which were not affected by high soil temperature. However, oleic acid was present in the smallest amount in leaves and roots and palmitoleic acid was the least in roots. Fatty acids with more double bonds are easily attacked by free radicals (Elstner, 1982; Foyer et al., 1994; Halliwel, 1984; Smirnoff, 1993). The decline in total fatty acid content in creeping bentgrass exposed to high soil temperature could be due to oxidative damage. Changes in the content of 16-C (Fig. 4) and 18-C (Figs. 5 and 6) fatty acids were similar in response to high soil temperature, suggesting that the difference in fatty acid size by 2 carbons had no effects on the sensitivity of those fatty acids to high soil temperature.

It is also interesting to note that the total fatty acid content 


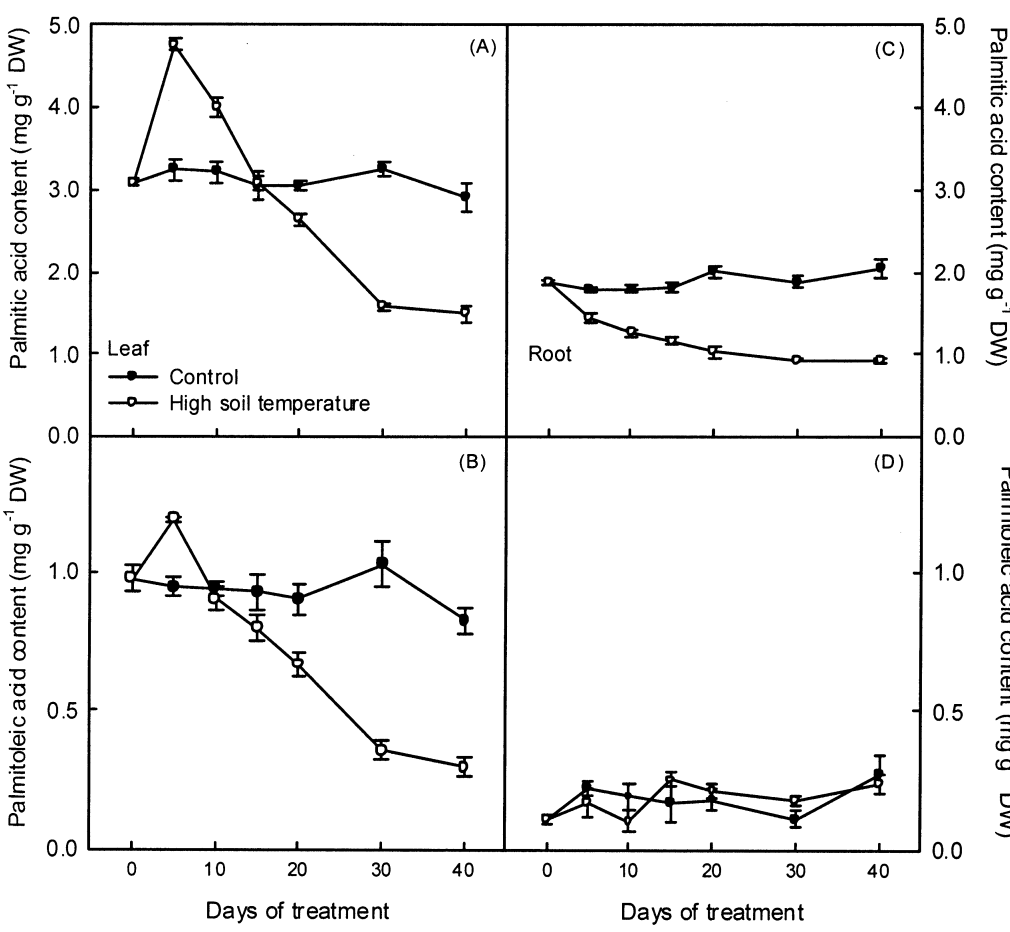

Fig. 4. Effects of high soil temperature on the content of 16-C fatty acids (palmictic and palmitoleic) in leaves (A) and roots (B) for creeping bentgrass. Fatty acid content was expressed as $\mathrm{mg}$ fatty acid per gram dry weight (DW) of tissues. Control $=$ air/soil temperature of $20 / 20^{\circ} \mathrm{C}$. High soil temperature $=$ air $/$ soil temperature of $20 / 35^{\circ} \mathrm{C}$. Vertical bars represent the values for the least significance difference at $P=0.05(\mathrm{n}=4)$ for treatment comparison at a given day of treatment.

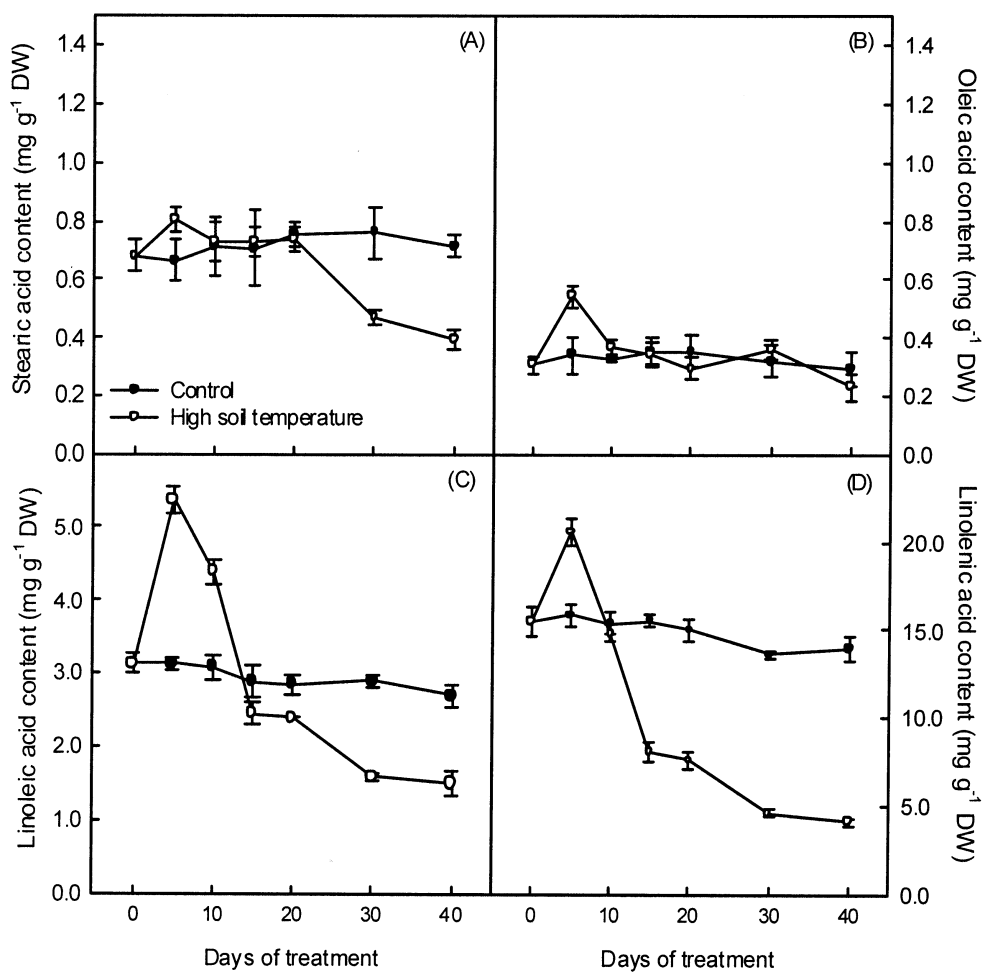

Fig. 5. Effects of high soil temperature on the content of 18-C fatty acids in leaves for creeping bentgrass: stearic (A), oleic (B), linoleic (C), and linolenic (D). Fatty acid content was expressed as mg fatty acid per gram dry weight (DW) of tissues. Control $=$ air/soil temperature of $20 / 20^{\circ} \mathrm{C}$. High soil temperature $=$ air/soil temperature of $20 / 35^{\circ} \mathrm{C}$. Vertical bars represent the values for the least significance difference at $P=0.05(\mathrm{n}=4)$ for treatment comparison at a given day of treatment. in leaves was about four times higher in leaves than in roots. Similar results have been reported in creeping bentgrass plants exposed to high air and soil temperature (Larkindale and Huang, 2004). Fatty acids in all membranes including thylakoid membranes and plasma membranes were extracted and counted in the total fatty acid in this study. Leaf tissues were packed with chloroplasts, an organelle containing a lot of lipid materials in the thylakoid membranes (Grove et al., 2000). The difference in total fatty acid content between leaves and roots could attribute to the thylakoid membranes of chloroplasts.

The double bond index (DBI) in leaves and roots decreased at high soil temperature (Fig. 7). This suggested that the level of saturation of fatty acids increased with increases in soil temperature. In this study, we found both content of unsaturated fatty acids and content of saturated fatty acids in leaves and roots decreased at high soil temperature. However, the decrease in unsaturated fatty acids was more dramatic than the decrease in saturated fatty acids, which resulted in a decrease of DBI. The decrease in DBI could be explained by the lipid peroxidation that resulted in the faster decrease of unsaturated fatty acid content. The increase in saturation level of fatty acids could increase membrane rigidity, thus maintaining integrity at high temperature (Murakami et al., 2000). It has been reported in creeping bentgrass and other plant species that heat stress can increase the level of saturation of fatty acids (Grove et al., 2000; Kunst et al., 1989; Larkindale and Huang, 2004; Murakami et al., 2000; Vigh et al., 1993).

In summary, unsaturated fatty acids were predominant in both leaves and roots and more sensitive to increases in soil temperature compared to saturated fatty acids. The decrease in fatty acid content could be related to the physiological damages or leaf senescence induced by exposing roots to high soil temperature. The saturation level of membrane fatty acids increased at high soil temperature, which could be related to heat stress acclimation. Selecting for creeping bentgrass plants with highly saturated fatty acids or high fatty acid content in roots and leaves would help plants to survive under high soil temperature conditions. The mechanisms and significance of transient increases in fatty acid of roots in response to increasing temperatures deserve further investigation.

\section{Literature Cited}

Alfonso, M., I. Yruela, S. Almárcegui, E. Torrado, M.A. Pérez, and R. Picorel. 2000. Unusual tolerance to high temperatures in a new herbicide-resistant D1 mutant from Glycine max $(\mathrm{L}$.) Merr. Cell cultures deficient in fatty acid desaturation. Planta. 212:573-582.

Blum, A. and A. Ebercon. 1981. Cell membrane stability as a measure of drought and heat tolerance in wheat. Crop Sci. 21:43-47.

Cyril, J., G.L. Powell, R.R. Duncan, and W.V. Baird. 2002. Changes in membrane polar lipid fatty acids of seashore paspalum in response to low temperature exposure. Crop Sci. 42:2031-2037.

Elstner, E.F. 1982. Oxygen activation and oxygen toxicity. Annu. Rev. Plant Physiol. 32:18-22. 


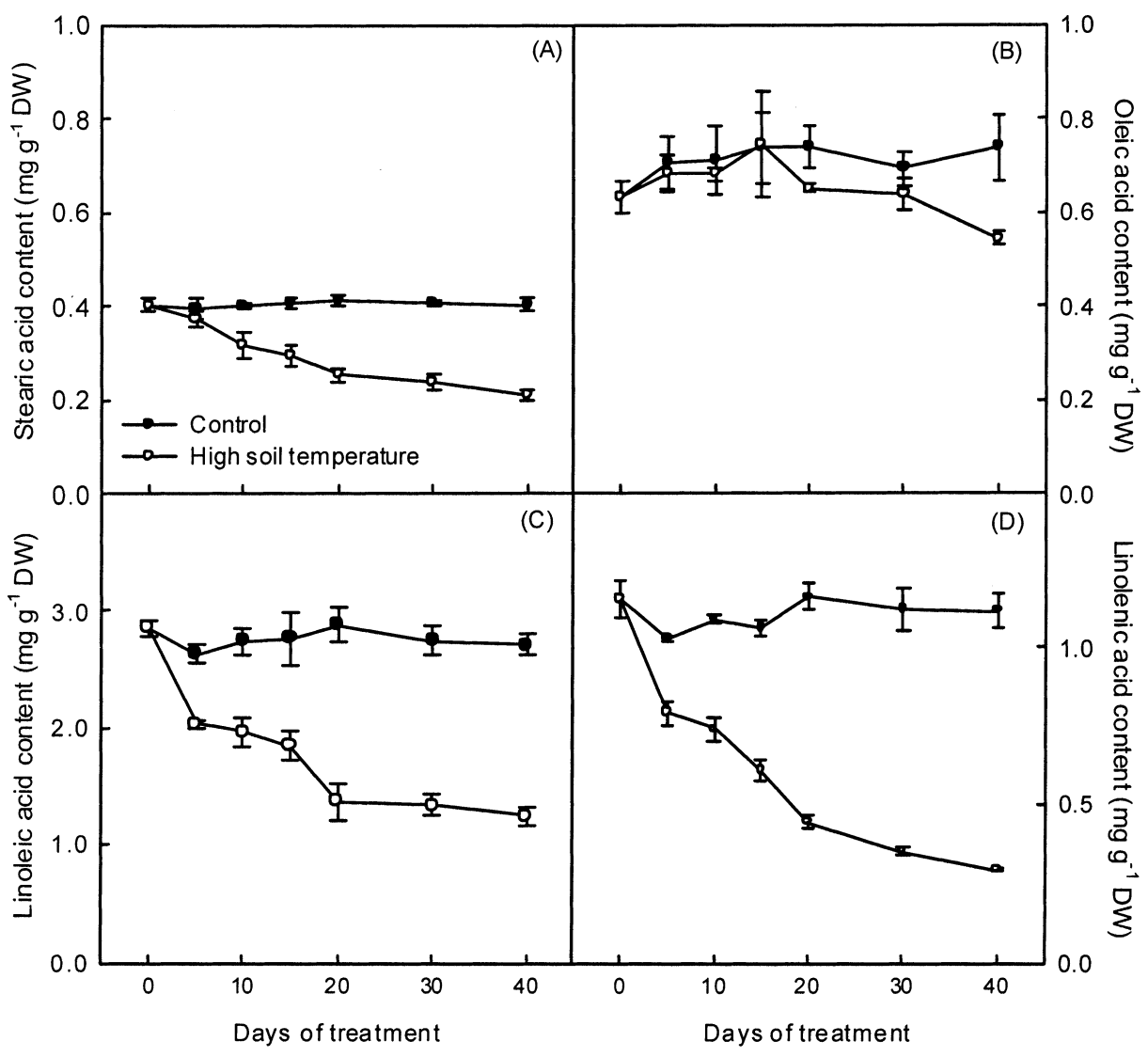

Fig. 6. Effects of high soil temperature on the content of 18-C fatty acids in roots for creeping bentgrass: stearic (A), oleic (B), linoleic (C), and linolenic (D). Fatty acid content was expressed as $\mathrm{mg}$ fatty acid per gram dry weight $(\mathrm{DW})$ of tissues. Control $=$ air/soil temperature of $20 / 20^{\circ} \mathrm{C}$. High soil temperature $=$ air/soil temperature of $20 / 35^{\circ} \mathrm{C}$. Vertical bars represent the values for the least significance difference at $P=0.05$ (n $=4$ ) for treatment comparison at a given day of treatment.

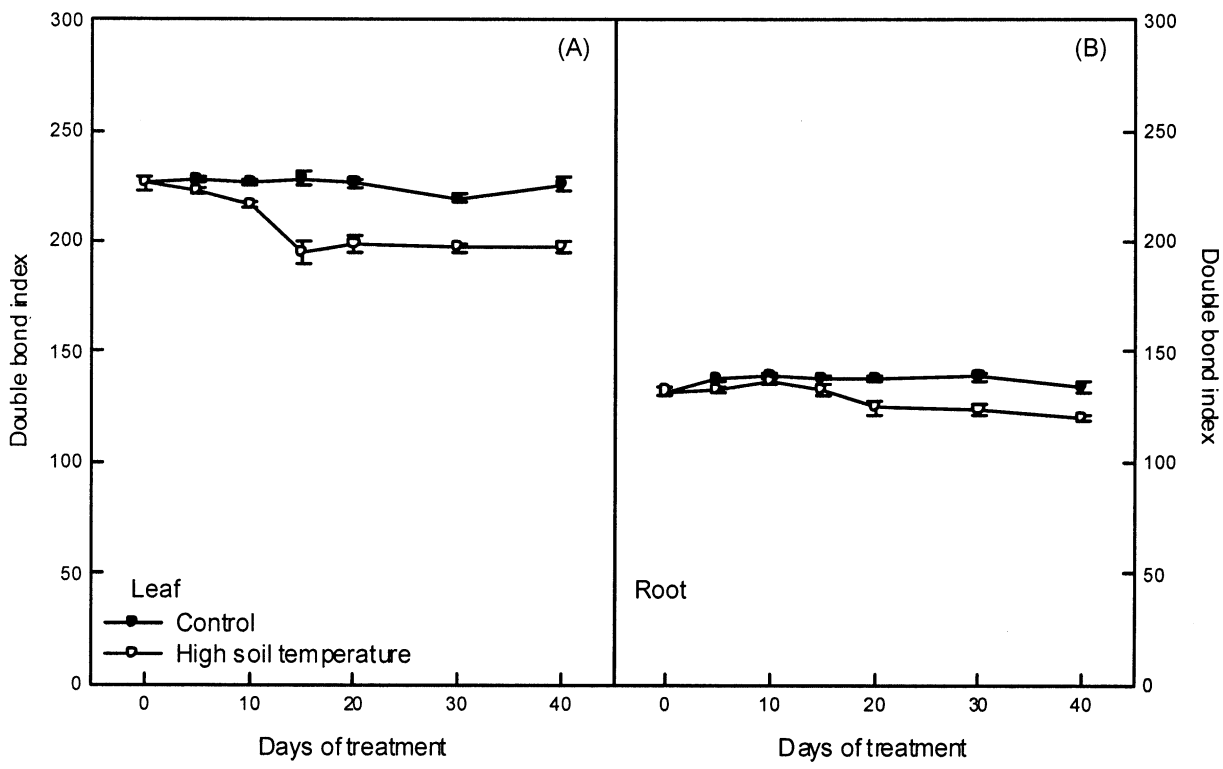

Fig. 7. Effects of high soil temperature on fatty acid saturation expressed as double bond index in leaves (A) and roots $(\mathbf{B})$ for creeping bentgrass. Vertical bars represent the values for the least significance difference at $P=0.05(\mathrm{n}=4)$ for treatment comparison at a given day of treatment.
Foyer, C.H., P. Descourvieres, and K.J. Kunert. 1994. Photooxidative stress in plants. Physiol. Plant. 92:696-717.

Fry , J.D. and B. Huang. 2004. Advanced turfgrass science and physiology. Wiley, New York.

Gombos, Z., H. Wada, E. Hideg, and N. Murata. 1994. The saturation of membrane lipids stabilizers photosynthesis against heat stress. Plant Physiol. 104:563-567.

Grove,A., M.Agarwal, S. Katiyar-Argarwal, C. Sahi, and S. Argarwal. 2000. Production of high temperature tolerant transgenic plant through manipulation of membrane lipids. Current Sci. 79:5-10.

Halliwell, B. 1984. Oxidative damage, lipid peroxidation and antioxidant protection in chloroplasts. Chem. Physics Lipids. 44:327-340.

Heath, R.L. and L. Packer. 1968. Photoperoxidation in isolated chloroplasts. I. Kinetics and stoichiometry of fatty acid peroxidation. Arch. Biochem. Biophys. 125:189-198.

Hoagland, C.R. and D.I. Arnon. 1950. The solution-culture method for growing plants without soil. Calif. Agr. Expt. Circ. 347.

Horvath, I., A. Glatz, V. Varvasovszki, T. Zsolt, T. Pali, G. Balogh, E. Kovacs, L. Nadasdi, S. Benko, F. Joo, and L. Vigh. 1998. Membrane physical state controls the signalling mechanism of the heat shock response in Syneschocystis PC 6803: Identification of HSP17 as a fluidity gene. Proc. Natl. Acad. Sci. 95:3513-3518.

Huang, B., X. Liu, and Q. Xu. 2001. Supraoptimal soil temperatures induced oxidative stress in leaves of creeping bentgrass cultivars differing in heat tolerance. Crop Sci. 41:430-435.

Hugly, S., L. Kunst, J. Browse, and C. Somerville. 1989. Enhanced thermal tolerance of photosynthesis and altered chloroplast ultrastructure in a mutant of Arabidopsis deficient in lipid desaturation. Plant Physiol. 90:1134-1142.

Kunst, J., J. Browse, and C. Somerville. 1989. Enhanced thermal tolerance in a mutant of Arabidopsis deficient in palmitic acid unsaturation. Plant Physiol. 91:401-408.

Kuroyanagi, T. and G.M. Paulsen. 1988. Mediation of high-temperature injury by roots and shoots during reproductive growth of wheat. Plant, Cell Environ. 11:517-523.

Larkindale, J. and B. Huang. 2004. Changes of lipid composition and saturation level in leaves and roots for heat-stressed and heatacclimated creeping bentgrass (Agrostis stolonifera). Expt. Environ. Bot. 51:57-67.

Liu, X. and B. Huang. 2002. Cytokinin fffects on creeping bentgrass response to heat stress. II. Leaf senescence and antioxidant metabolism. Crop Sci. 42:466-472.

Marcum, K.B. 1998. Cell membrane thermostability and whole plant heat tolerance of Kentucky bluegrass. Crop Sci. 38:1214-1218.

Murakami, Y., M. Tsuyama, Y. Kobayashi, 
H. Kodama, and K Iba. 2000. Trienoic fatty acids and plant tolerance of high temperature. Science 287:476-479.

Paulsen, G.M. 1994. High temperature responses of crop plants, p. 365-389. In: K.J. Boote, J.M. Bennett, T.R. Sinclair, and G.M. Paulsen (eds.). Physiology and determination of crop yield. ASA, CSSA and SSSA, Madison, Wis.

Pearcy, R. 1978. Effect of growth temperature on the fatty acid composition of the leaf lipids in Atriplex lentiformis (Torr.) Wats. Plant Physiol. 61:484-486.

Peters, J.S. and C.K. Chin. 2003. Inhibition of photosynthetic electron transport by palmitoleic acid is partially correlated to loss of thylakoid membrane proteins. Plant Physiol. Biochem. 41:117-124.

Raison, J.K., J.K.M. Roberts, and J.A. Berry. 1982. Correlation between the thermal stability if chloroplast (thylakoid) membranes and composition and fluidity of their polar lipids upon acclimation of the higher plant, Nerium oleander, to growth temperature. Biochim Biophys Acta. 688:218-228.

Ruter,J.M. and D.L. Ingram. 1992. High root-zone temperatures influence RuBisCO activity and pigment accumulation in leaves of 'Rotundifolia' holly. J. Amer. Soc. Hort. Sci. 117:154-157.

Schreiber, U. and W. Bilger. 1987. Rapid assessment of stress effects on plant leaves by chlorophyll fluorescence measurement, p. 27-53. In: J.D. Tenhunen, F.M. Catarino, O.L. Lange, and W.C. Oechel (eds.). Plant responses to stress-Functional analysis in Mediterranean ecosystems. Springer-Verlag, Heidelberg. Germany.

Sharkey, T.D. 2000. Some like it hot. Science 287:435-437.

Smirnoff, N. 1993. The role of active oxygen in the responses of plants to water deficit and desiccation. New Phytol. 125:27-58.

Thomas, H., H. Ougham, P. Canter, and J. Donnison. 2002. What stay- green mutants tell us about nitrogen remobilization in leaf senescence? J. Expt. Bot. 53:801-808.

Thomas, P.G., P.J. Dominy, L. Vigh, A.R. Mansourian, P.J. Quinn, and W.P. Williams. 1986. Increased thermal stability of pigment-protein complexes of pea thylakoids following catalytic hydrogenetion of membrane lipids. Biochim Biophys Acta. 849:131-136.

Udomprasert, N., P.H. Li, D.V. Davis, and A.H. Markhart III. 1995. Root cytokinin level in relation to heat tolerance of Phaseolus acutifolius and Phaseolus vulgaris. Crop Sci. 35:486-490.

Vassilev, A., F. Lidon, P. Scotti Campos, J.C. Ramalho, M.G. Barreiro, and I. Yordanov. 2003. Cu-induced changes in chloroplast lipids and photosystem 2 activity in barley plants. Bulgaria J. Plant Physiol. 29:33-43.

Vigh, L., D.A. Los, I. Horvath, and N. Murata. 1993. The primary signal in the biological perception of temperature:Pd catalyzed hydrogenation of the membrane lipids stimulated the expression of the desA gene in Synecchocyctis PC6803. Proc. Natl. Acad. Sci. 90:9090-9094.

Wang, Z., Q. Xu, and B. Huang. 2004. Endogenous cytokinin levels and growth responses to extended photoperiods for creeping bentgrass under heat stress. Crop Sci. 44:209-213.

Xu, Q., and B. Huang. 2000a. Growth and physiological responses of creeping bentgrass to changes in air and soil temperatures. Crop Sci. 40:1363-1368.

Xu, Q. and B. Huang. 2000b. Effects of differential air and soil temperature on carbohydrate metabolism in creeping bentgrass. Crop Sci. 40:1368-1374.

Ziska, L.A. 1998. The influence of root zone temperature on photosynthetic acclimation to elevated carbon dioxide concentrations. Ann. Bot. (London) 81:717-721. 